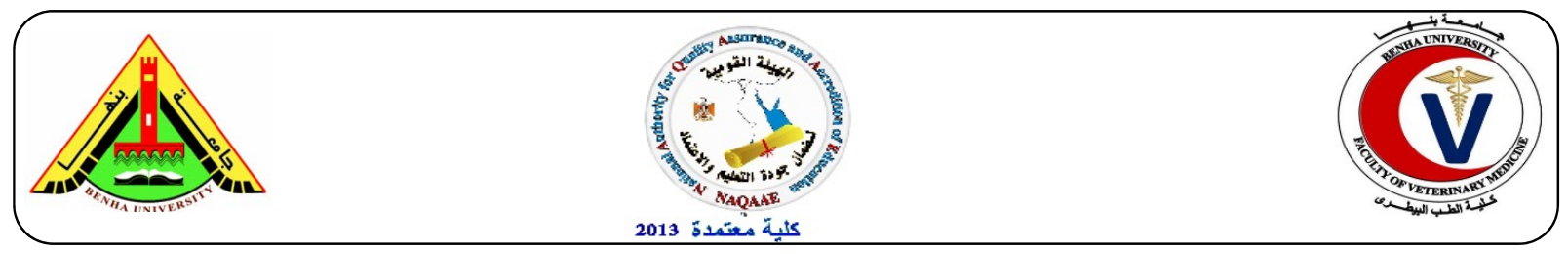

\title{
Efficacy of inactivated BEF vaccine adjuvant with Montanide ISA 206 compared with the locally prepared inactivated BEF vaccines.
}

\author{
El-Bagoury, G.F. ${ }^{1}$; El-Habbaa, A.S. ${ }^{1}$; Amal, A.M. ${ }^{2}$; Nermeen, G.S. ${ }^{2}$ \\ ${ }^{1}$ Department of Virology, Faculty of Veterinary Medicine, Benha University. \\ ${ }^{2}$ Central Laboratory for Evaluation of Veterinary Biologics, Abbassia, Cairo.
}

\begin{abstract}
A B S T R A C T
Bovine ephemeral fever (BEF) virus belonging to Ephemerovirus genus of the Rhabdoviridae family causes an economically important seasonal acute vector- borne disease. Routine vaccination, is one of the main controlling steps, particularly in countries where the disease is endemic. This study deal with comparative evaluation of humeral immune response of cattle using SNT and ELISA to three inactivated BEF vaccines. Inactivated BEF vaccine with Montanide ISA 206 (water-in-oil-in-water) adjuvant given in 2 doses one month apart gave high protective antibody titer lasted for 44 weeks' post vaccination (WPV). The inactivated BEF vaccine with aluminum hydroxide gel adjuvant given in 2 doses one month apart gave satisfactory immune response lasted for 30 WPV then neutralizing antibodies waned rapidly. Live attenuated BEF vaccine that inactivated by saponin on time of vaccination give higher antibody titer which rise more rapidly lasted for $38 \mathrm{WPV}$ only. It could be concluding that the inactivated BEF vaccine with Montanide ISA 206 adjuvant gave satisfactory higher and longer lasting antibody titer for 44 WPV and it was recommended to use this vaccine in endemic and non-endemic countries to control and prevent the disease especially before summer season.
\end{abstract}

KEYWORDS: BEF virus, Vaccine, Adjuvant, SNT, ELISA.

(http://www.bvmj.bu.edu.eg)

(BVMJ-31(2): 117-123, 2016)

\section{INTRODUCTION}

Bovine ephemeral fever (BEF) virus belonged to genus Ephemerovirus of the family Rhabdoviridae, has been isolated from mosquitoes and Culicoides biting midges and causes an economically important seasonal acute vector borne disease (Kirland, 1995; Mellor, 1996). BEF disease is characterized by biphasic fever, depression, lameness, recumbency, joint swelling, rear limb paralysis, nasal and ocular discharge, excessive salivation, stiffness, sudden drop in milk production and spontaneous recovery in three days. The disease spreads through subtropical and temperate regions of the Middle East, Asia, Africa, and Australia (Finlaison et al., 2010). BEF virus possesses a single stranded, negative-sense RNA genome and five structural proteins comprising a nucleoprotein $(\mathrm{N})$, a polymerase-associated protein $(\mathrm{P})$, a matrix protein (M), a large RNA-dependent RNA polymerase (L) and a glycoprotein (G) spanning the viral envelope (Walker et al., 1991). A glycoprotein $(G)$ is a type-specific neutralizing antigen and induces protective immunity in cattle (Uren et al., 1994), the $\mathrm{N}$ protein is also immunogenic in cattle but it does not induce virusneutralizing antibodies or a protective response, it induces a $\mathrm{T}$ cell proliferative response in cattle (Uren et al., 1993). Control of BEF disease depend mainly on, restricted cattle movement, a brief quarantine period in a vector-free area beside vector control, treatment and vaccination. To date four types of BEF vaccine have been developed live attenuated, inactivated, $G$ protein-based sub-unit and recombinant vaccines but the most commercially used types are live attenuated and inactivated vaccines (Walker and Klement, 2015). Live attenuated BEF vaccine have been used in many endemic countries that produced a long-lasting neutralizing antibody (Tzipori and Spradbrow, 1973), but their use was discouraged owing to their potential lack of safety because the virus might backmutate to its virulent form (Muskett et al., 1985). Inactivated BEF vaccine adsorbed on aluminum phosphate gel (Inaba et al., 1973) and water-in-oilin-water adjuvant (Aziz-Boaron et al., 2013) were likewise utilized. In Egypt, binary ethylene imine inactivated BEF vaccine with aluminum hydroxide gel adjuvant and attenuated BEF vaccine inactivated on the time of vaccination using saponin were applied in the field (El-Behwar et al., 2010). Although experimental and commercial $\mathrm{BEF}$ vaccines have been developed in different formulations, there is a need for further researches to 
provide a more informed evaluation of the vaccine performance (Walker and Klement, 2015).

In this study an inactivated BEF vaccine was prepared using Montanide ISA 206 (water-in-oil-inwater) as adjuvant, examined for sterility and safety then evaluated for humeral immune response in calves through follow up of antibody titers for 48 weeks using SNT and ELISA, in comparison to other locally prepared inactivated gel adjuvant BEF vaccines.

\section{MATERIAL AND METHODS}

\subsection{BEF virus strain:}

It was isolated from Toukh Tambasha, Monofia Governorate, Egypt during the outbreak that occurred in summer 2000 (Soad et al., 2001). This isolate designed as Abbassia virus strain (BEF/AVS/2000) was supplied by Veterinary Serum and Vaccine Research Institute, Abbassia, Cairo, Egypt and used as the seed for vaccine preparation after its adaptation to tissue culture.

\subsection{BEF Vaccines:}

\subsubsection{Local inactivated BEF vaccine with aluminum hydroxide gel as adjuvante:}

It was supplied by the Department of Pet Animal Vaccine Research, Veterinary Serum and Vaccine Research, Institute, Abbassia, Cairo $\left(10^{8}\right.$ tissue culture adapted virus vaccine).

\subsubsection{Local live attenuated BEF vaccine inactivated on time of vaccination using saponin:}

It was supplied by the Department of Pet Animal Vaccine Research, Veterinary Serum and Vaccine Research, Institute, Abbassia, Cairo $\left(10^{8}\right.$ tissue culture adapted virus vaccine.

\subsection{Saponin:}

It was supplied under the cat. no. 16109; lot. 71500 by sigma-Aldrish Labochemikalien $\mathrm{Gm} 6 \mathrm{H}$; Germany. It was supplied as $0.2 \mu \mathrm{g}$ saponin $/ \mathrm{ml}$ with phosphate buffered saline (PBS) and was used as a diluent to inactivate the live attenuate BEF virus vaccine at the time of vaccination and injected directly after reconstitution.

\subsection{Cell line:}

Baby Hamster Kidney cell line $\left(\mathrm{BHK}_{21}\right.$ clone 13$)$ was supplied by the Animal Research Institute, Pirbright, UK. It was propagated at FMD Department, Veterinary Serum and Vaccine Research, Institute, Abbasia, Cairo, Egypt by using of minimum Essential Medium (MEM) with Eagle's salts and with $10 \%$ new born calf serum according to (Macpherson and Stocker, 1962). These cells were used for virus propagation and titration and also for SNT

\subsection{Vaccine formulation:}

BEF virus was inoculated on BHK-21 cell line that harvested at over $70 \%$ cytopathic effect after 30-35 h, then it was purified by centrifugation at $3000 \mathrm{rpm}$ for 20 minutes to remove cell debris (Killington et al., 1996). Titer of the tissue culture adapted virus was estimated on BHK21 cell line (Reed and Muench, 1938) and its antigenicity was titrated using complement fixation test (CFT), (Traub and Manso, 1944). The seed BEF virus had a titer of $10^{8} \mathrm{TCID} 50 / \mathrm{ml}$ and 64 using infectivity titration and CFT, respectively. It was inactivated by binary ethylene imine (BEI) and the vaccine formulation was carried out where the oil phase consisted of Montanide ISA 206, mixed as equal parts of an aqueous and oil phase weight/weight, and mixed to make water-in-oil-in-water suspension (Barnett et al., 1998).

\subsection{Quality control of the prepared vaccine:}

Sterility and safety was evaluated for the prepared inactivated BEF vaccine according to (Code of Federal Regulation of USA, 1986). Sterility test was applied to confirm that the prepared vaccine was free from bacterial and fungal contamination using nutrient agar, thioglycolate broth (for bacterial detection) and Sabouraud's dextrose agar (for fungal detection). Safety of the inactivated BEF virus before addition of adjuvant, was applied on tissue culture and the safety of the prepared vaccine after adjuvant was applied by injection 10x dose of the vaccine in calves by subcutaneous $(\mathrm{S} / \mathrm{C})$ route.

\subsection{Calves and experimental design:}

Nineteen male calves (local breed) aged between 9-10 months old about $300 \mathrm{~kg}$ body weights were used for evaluation of the prepared inactivated BEF vaccine with Montanide ISA206 adjuvant in comparison to other local BEF vaccines as follow: Group (1): Five calves vaccinated with $2 \mathrm{ml} /$ animal of the prepared oil vaccine by subcutaneous $(\mathrm{S} / \mathrm{C})$ route and boostered after one month. Group (2): Five calves vaccinated with $2 \mathrm{ml} /$ animal $(\mathrm{S} / \mathrm{C})$ of the local inactivated BEF vaccine adjuvant with aluminum hydroxide gel and boostered after one month. Group (3): Five calves vaccinated $(\mathrm{S} / \mathrm{C})$ with the local live attenuated lyophilized BEF vaccine reconstituted in PBS containing $0.2 \mu \mathrm{g}$ saponin $/ \mathrm{ml}$ used as a diluent to inactivated the virus on time of vaccination. Group (4): Two calves were kept as control without vaccination. Group (5): Two calves were used in safety test of the prepared vaccine. Sera from 
vaccinated cattle groups were used to measure the variance in efficacy and duration of immunity between different BEF vaccines for 48 weeks, using SNT and ELISA test.

\subsection{Serum neutralization test (SNT):}

SNT was performed using the micro-technique to detect neutralizing antibodies against BEF virus. The antibody titer was estimated as the reciprocal of the final serum dilution which neutralized and inhibited the CPE of 100 TCID $_{50}$ of BEF virus (Mellor, 2001).

\subsection{Enzyme Linked Immunosorbent Assay (ELISA):}

BEF antigen was prepared from infected BHK 21 cells and concentrated by PEG (6000) according to (Wagner et al., 1969), then used in ELISA to estimate the specific antibodies of BEF virus (Zakrzewski et al., 1992).

\section{RESULTS}

\subsection{Sterility and safety of the vaccine:}

The prepared vaccine gave satisfactory results being free from aerobic and anaerobic bacteria and fungi. The prepared vaccine was safe and gave satisfactory results after tested on tissue culture with no appearance of cytopathic effect, and no rise in body temperature of vaccinated calves group (4).

\subsection{Immunological response:}

For calves in group (1), SNT results showed that protective neutralizing serum antibody titer (1.2) started from $2^{\text {nd }} \mathrm{WPV}$, reached highest titer at $12^{\text {th }}$ WPV and persisted in protective titer till $44^{\text {th }} \mathrm{WPV}$, as shown in table (1) and figure (1); ELISA results showed that positive serum antibody level started from $2^{\text {nd }} \mathrm{WPV}$, reached highest level at $12^{\text {th }} \mathrm{WPV}$ and persisted positive till $48^{\text {th }} \mathrm{WPV}$, as shown in table (2) and figure (2).

For calves in group (2), SNT results showed that protective neutralizing serum antibody titer (1.2) started from $2^{\text {nd }} \mathrm{WPV}$, reached highest titer at $10^{\text {th }}$ WPV and persisted in protective titer till $30^{\text {th }} \mathrm{WPV}$, as shown in table (1) and figure (1); ELISA results showed that positive serum antibody level started from $2^{\text {nd }} \mathrm{WPV}$, reached highest level at $10^{\text {th }} \mathrm{WPV}$ and persisted positive till $30^{\text {th }} \mathrm{WPV}$, as shown in table (2) and figure (2).

Table (1): Mean serum neutralizing antibody titers for BEF virus in sera from calves vaccinated with different types of BEF vaccines using SNT.

\begin{tabular}{|c|c|c|c|c|}
\hline \multirow{2}{*}{$\begin{array}{l}\text { Weeks } \\
\text { post } \\
\text { vaccination }\end{array}$} & \multicolumn{4}{|c|}{$\begin{array}{l}\text { Mean } \log _{10} \\
\text { serum neutralizing antibody titers }\end{array}$} \\
\hline & Group 1 & Group 2 & Group 3 & Control \\
\hline 1 & $* 0.75$ & 0.86 & 0.9 & 0 \\
\hline 2 & 1.35 & 1.35 & 1.47 & 0 \\
\hline 3 & 1.65 & 1.47 & 1.89 & 0 \\
\hline 4 & 1.98 & 1.67 & 2.07 & 0 \\
\hline 6 & 2.4 & 1.86 & 2.4 & 0 \\
\hline 8 & 2.52 & 2.07 & 2.76 & 0 \\
\hline 10 & 2.61 & 2.34 & 2.67 & 0 \\
\hline 12 & 2.7 & 2.13 & 2.58 & 0 \\
\hline 14 & 2.58 & 2.04 & 2.34 & 0 \\
\hline 16 & 2.43 & 1.97 & 2.19 & 0 \\
\hline 18 & 2.34 & 1.85 & 2.04 & 0 \\
\hline 20 & 2.07 & 1.76 & 1.92 & 0 \\
\hline 22 & 2.01 & 1.61 & 1.79 & 0 \\
\hline 24 & 1.89 & 1.53 & 1.78 & 0 \\
\hline 26 & 1.83 & 1.41 & 1.55 & 0 \\
\hline 28 & 1.74 & 1.36 & 1.47 & 0 \\
\hline 30 & 1.62 & 1.26 & 1.38 & 0 \\
\hline 32 & 1.56 & 1.12 & 1.33 & 0 \\
\hline 34 & 1.5 & 1.08 & 1.25 & 0 \\
\hline 38 & 1.41 & 0.93 & 1.21 & 0 \\
\hline 40 & 1.29 & 0.72 & 0.69 & 0 \\
\hline 44 & 1.23 & 0.3 & 0.33 & 0 \\
\hline 48 & 0.99 & 0 & 0.12 & 0 \\
\hline
\end{tabular}




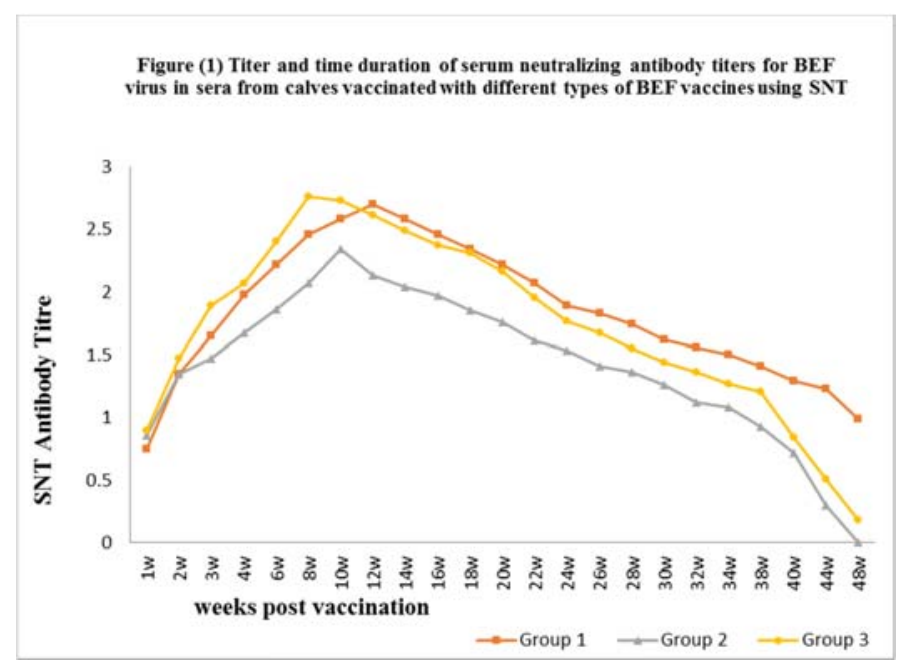

Table (2): Mean serum antibody levels for BEF virus in sera from calves vaccinated with different types of BEF vaccines using ELISA

\begin{tabular}{lllll}
\hline $\begin{array}{l}\text { Weeks } \\
\text { post }\end{array}$ & \multicolumn{4}{l}{$\begin{array}{l}\text { Mean optical density for sera } \\
\text { of vaccinated calves using ELISA }\end{array}$} \\
vaccination & Group 1 & Group 2 & Group 3 & Control \\
\hline 1 & 0.9194 & 0.9034 & 1.0066 & 0.220 \\
2 & 1.2256 & 1.0178 & 1.8654 & 0.214 \\
3 & 1.7614 & 1.2194 & 2.2666 & 0.204 \\
4 & 2.1826 & 1.4364 & 2.8362 & 0.215 \\
6 & 2.5752 & 1.637 & 3.1028 & 0.198 \\
8 & 2.8658 & 2.2024 & 3.354 & 0.213 \\
10 & 2.9676 & 2.4176 & 3.3308 & 0.224 \\
12 & 3.0928 & 2.2686 & 3.136 & 0.223 \\
14 & 2.8436 & 2.0976 & 2.9294 & 0.196 \\
16 & 2.713 & 1.8758 & 2.7508 & 0.198 \\
18 & 2.6256 & 1.5736 & 2.5348 & 0.213 \\
20 & 2.5186 & 1.3676 & 2.3608 & 0.190 \\
22 & 2.4582 & 1.305 & 2.1958 & 0.210 \\
24 & 2.3678 & 1.2642 & 2.0948 & 0.193 \\
26 & 2.1476 & 1.1744 & 1.9032 & 0.196 \\
28 & 1.9446 & 1.1162 & 1.7538 & 0.204 \\
30 & 1.6974 & 1.0724 & 1.6204 & 0.190 \\
32 & 1.545 & 0.9846 & 1.4028 & 0.202 \\
34 & 1.3288 & 0.9172 & 1.114 & 0.197 \\
38 & 1.1504 & 0.796 & 1.0228 & 0.203 \\
40 & 1.1222 & 0.5356 & 0.762 & 0.193 \\
44 & 1.067 & 0.305 & 0.373 & 0.194 \\
48 & 1.016 & 0.2142 & 0.2824 & 0.198 \\
\hline
\end{tabular}

Positive serum antibody level over one.

For calves in group (3), SNT results showed that protective neutralizing serum antibody titer (1.2) started from $2^{\text {nd }} W P V$, reached highest titer at $8^{\text {th }}$ WPV and persisted in protective titer till $38^{\text {th }}$ Weeks PV, as shown in table (1) and figure (1); ELISA results showed that positive serum antibody level started from first WPV, reached highest level at $8^{\text {th }} \mathrm{WPV}$ and persisted positive till $38^{\text {th }} \mathrm{WPV}$, as shown in table (2) and figure (2). These results were shown in comparison to that of the calves kept as control non-vaccinated Group (3) that gave negative results. 


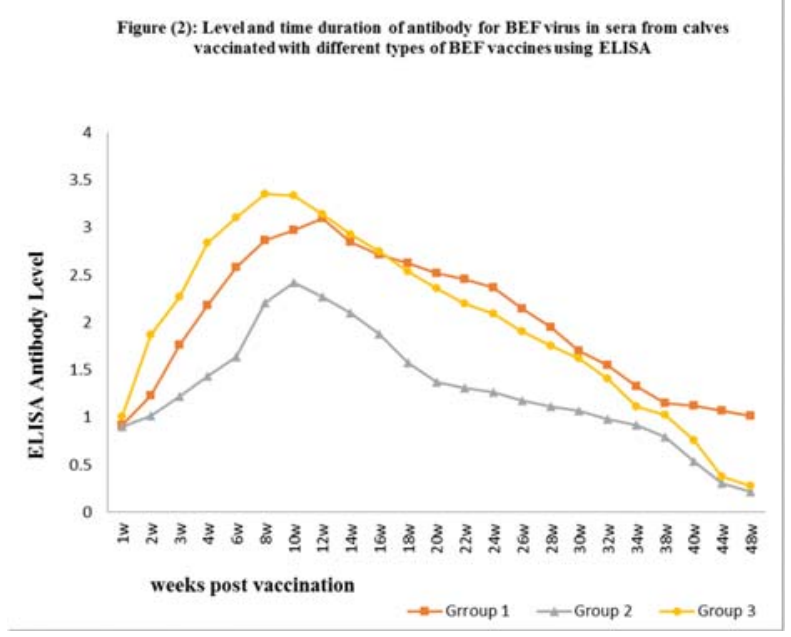

\section{DISSCUSSION}

In Egypt, many outbreaks of BEF were reported native and imported breeds of cattle (Al-Gaabary et al., 2005 ; Davies et al., 1993; El-Bagoury et al., 2014; Hassan, 2000; Kawther and Wahid, 2011). Routine vaccination, as one of the main controlling steps, is a critical tool in controlling BEF disease, particularly in countries where the disease is endemic. This study deal with comparative evaluation of humeral immune response of cattle to three types of BEF vaccines including inactivated vaccine with ISA 206 oil adjuvant, inactivated vaccine with aluminum gel adjuvant and live attenuated vaccine inactivated at time of vaccination using saponin. Testing sterility of the prepared inactivated BEF vaccine with ISA 206 oil adjuvant showed its freedom of foreign contaminants (bacteria and fungi) (Code of Federal Regulation of USA, 1986).

The prepared inactivated BEF vaccine proved to be safe in tissue culture with satisfactory results with no cytopathic effect, and it gave also satisfactory results of safety in calves with no rise in body temperature and no clinical abnormalities (Henderson, 1970). For calves in group (1) inoculated with the prepared inactivated BEF vaccine, protective neutralizing serum antibody titer (1.35) started from $2^{\text {nd }} \mathrm{WPV}$, reached highest titer at $12^{\text {th }} \mathrm{WPV}$ and persisted in protective titer (1.23) till $44^{\text {th }}$ WPV using SNT while ELISA results showed that positive serum antibody level started from $2^{\text {nd }} \mathrm{WPV}$, reached highest level at $12^{\text {th }}$ WPV and persisted positive (1.016) till $48^{\text {th }} \mathrm{WPV}$. It was recorded that vaccine prepared from low and high passage BEF virus emulsified with Freund's incomplete mineral oil adjuvant could induce high neutralizing antibodies in vaccinated cattle which could be detectable for at least a year (Theodoridis et al., 1973), especially in case of boostering that gave longer antibody response and higher titer than single injection (Cameron et al., 1987). Vaccines adjuvanted with Montanide ISA 206 can promote longer lasting immunity than conventional vaccines adjuvant with Alhydragel in ruminant persisted for at least 6 months PV (Barnett et al., 1996; Hunter, 1996).

For calves in group (2) inoculated with the local inactivated BEF vaccine with aluminum hydroxide gel adjuvant, protective neutralizing serum antibody titer (1.35) started from $2^{\text {nd }} \mathrm{WPV}$, reached highest titer at $10^{\text {th }} \mathrm{WPV}$ and persisted in protective titer (1.26) till $30^{\text {th }} \mathrm{WPV}$, using SNT while ELISA results showed that positive serum antibody level (1.0178) started from $2^{\text {nd }} \mathrm{WPV}$, reached highest level at $10^{\text {th }} \mathrm{WPV}$ and persisted positive $(1.0724)$ till $30^{\text {th }} \mathrm{WPV}$. Formalin inactivated, aluminum phosphate gel-adsorbed vaccine developed in Japan was shown to elicit a strong antibody response after two doses but immunity waned rapidly and neutralizing antibody was no longer detected in most animals (Inaba et al., 1973), and it was found also that oil emulsion FMD vaccine (double oil emulsion) gave best results in comparison with AL $(\mathrm{OH}) 3$ vaccine (Barteling and Vreswij, 1991).

Antiviral activity of saponin was studied in vitro against some viruses where it was found to inhibit the replication of herpes simplex virus type 1(HSV-1) and poliovirus type 2 as shown by inhibition of cytopathic effect and reduction of virus production. In addition, saponin action involves inhibition of virus-host cell attachment and interferes with both early and late events of virus replication (Amoros et al., 1987). Also its effect might be the cause of inhibition of virus penetration and protein synthesis (Hayashi et al., 1997). 
For calves in group (3) inoculated with live attenuated BEF Virus vaccine which inactivated by saponin at time of vaccination, SNT results showed that protective neutralizing serum antibody titer (1.47) started from $2^{\text {nd }} \mathrm{WPV}$, reached highest titer at $8^{\text {th }} \mathrm{WPV}$ and persisted in protective titer (1.21) till $38^{\text {th }} \mathrm{WPV}$, using SNT while ELISA results showed that positive serum antibody level (1.006) started from first WPV, reached highest level at $8^{\text {th }}$ WPV and persisted positive (1.0228) till $38^{\text {th }}$ WPV. These results agreed with those obtained by Black (1997) who indicated that saponin was a more efficient adjuvant than aluminum hydroxide gel where antibodies are higher when saponin was used. Also Samuikenko et al. (1982) found that saponin in an aluminum hydroxide gel, formaldehyde treated FMD vaccine raised the protection and neutralizing antibody titers. Although live attenuated BEF vaccine inactivated by saponin on time of vaccination gave rapid rise of higher antibody titer persisted for $38^{\text {th }} \mathrm{WPV}$ that recommended to use in case of outbreaks to control the disease but inactivated BEF vaccine with Montanide ISA206 adjuvant gave longer duration of immunity. The inactivated BEF vaccine with aluminum hydroxide gel adjuvant gave satisfactory immune response for $30^{\text {th }}$ WPV but it waned rapidly and neutralizing antibody was no longer detected as in case of other two tested vaccines.

Finally, we can conclude that the inactivated BEF vaccine with Montanide ISA 206 (water-inoil-in-water) adjuvant gave higher and longer duration antibody titer for $44^{\text {th }}$ WPV after two vaccinations one month apart, that it was recommended to use this vaccine in endemic and non-endemic countries to control and prevent the disease especially before summer season.

\section{REFERENCES}

Al-Gaabary, M.H., Osman, S.A., Foad, F., 2005 Comparative clinical and epidemiological studies on bovine ephemeral fever in Sakha farm, KafrEl-Sheikh, Egypt. Assiut Veterinary Medical Journal 51, 76-85.

Amoros, M., Fauconnier, B., Girre, R.L., 1987. In vitro antiviral activity of a saponin from Anagallisarvensis, Primulaceae, against herpes simplex virus and poliovirus. Antiviral Res. 8, 13-25.

Aziz-Boaron, O., Leibovitz, K., Gelman, B., Kedmi, M., Klement, E., 2013. Safety, immunogenicity and duration of immunity elicited by an inactivated bovine ephemeral fever vaccine. PLoS One 8, e82217.
Barnett, P.V., Pullen, L., Warder, P., Stathen, R., 1998. International bank for foot and mouth disease vaccine (preliminary studies on emergency foot and mouth disease vaccines formulated with montanide IMS Immunosol-, a new concept in oil adjuvancy. European commission for the control of FMD. Aldershot, United Kingdom.

Barnett, P.V., Pullen, L., Williams, L., Doel, T.R., 1996. International bank for foot-and-mouth disease vaccine: Assessment of Montanide ISA 25 and ISA 206, two commercially available oil adjuvants. Vaccine 14, 11871198.

Barteling, S.J., Vreswij, K.J., 1991. Development in foot and mouth disease vaccine. Vaccine 9, 75-88.

Black, L., 1997. FMD vaccination. Vet. Rec. 100, 195-198.

Cameron, C.M., Barnard, B.J.H., Erasmus, E., Botha, W.J.S., 1987. Antibody response in cattle to oil emulsion rabies and ephemeral fever vaccines. Onderstepoort journal of veterinary research 54, 157-158.

Code of Federal Regulation of USA, 1986. Published by the office of the federal register national archives and Record administration. Animal and animal products.

Davies, F.G., Moussa, A., Barsoum, G., 1993. The 1990-1991 epidemic of ephemeral fever in Egypt and the potential for spread to the Mediterranean region.Bovine ephemeral fever and related rhabdoviruses, In: Proceedings of the 1st International Symposium held in Beijing, Beijing, pp. 5456.

El-Bagoury, G.F., El-Nahas, E.M., El-Habbaa, A.S., 2014. Serological and molecular identification of Bovine Ephemeral Fever virus isolates from cattle and buffaloes in Qaluobia province, Egypt 2014. Egyptian Journal of Virology 11, 176-182.

El-Behwar, A.M., Nermin, G.S., Saad, M.A., Ibrahim, M.M., Magda, S.M., Anhar, A., Khodeir, M.H., 2010. Comparative evaluation of the potency of traditionally inactivated Bovine Ephemeral Fever vaccine and that one inactivated on the time of vaccination, In: 14th scientific conference of Faculty of veterinary medicine Assiut University, Egypt, pp. 51-61.

Finlaison, D.S., Read, A.J., Kirkland, P.D., 2010. An epizootic of bovine ephemeral fever in New South Wales in 2008 associated with long-distance dispersal of vectors. Aust Vet J 88, 301-306. 
Hassan, H.Y., 2000. An outbreak of bovine ephemeral fever in Egypt during 2000. II. Clinico-chemical and hematological alternations. Assiut Univ. Egypt., Fac. Vet. Med., pp. 354-356.

Hayashi, K., Hayashi, H., Hiraoka, N., 1997. Inhibitory activity of soyasaponin II on virus replication in vitro. Plant Med 63, 102-106.

Henderson, W.M., 1970. Foot and mouth disease; a definite ion of the problem and view on its solution. Br.Vet. J. 126, 115-120.

Hunter, P., 1996. The performance of Southern African Territories serotypes of foot and mouth disease antigen in oil adjuvanted vaccine. Rev.Sci.Tech., 15, 913-922.

Inaba, Y., Kurogi, H., Sato, K., Goto, Y., T.;, O., Matumoto, M., 1973. Formalin inactivated, aluminium phosphate gel-adsorbed vaccine of bovine ephemeral fever virus. Arch GesamteVirusforsch 42, 42-53.

Kawther, S.Z., Wahid, M.A., 2011. Investigation of Bovine Ephemeral Fever Virus in Egyptian cows and buffaloes with emphasis on isolation and identification of a field strain. Global Veterinaria 6, 447- 425.

Killington, R.A., Stokes, A., Hierolzer, 1996. Virology methods manual. Chapter 4: 72-89.

Kirland, P.D., 1995. The epidemiology of bovine ephemeral fever in Southwestern Australia: evidence for a mosquito vector. In 1st International Symposium (Beijing) on bovine ephemeral fever and related arboviruses. ACIAR Proceedings, Canberra 44, 33-37.

Mellor, P.S., 1996. Culicoides: vectors, climate change and disease risk. Vet. Bull. 66, 301306.

Mellor, P.S., 2001. Bovine ephemeral fever. In encyclopedia of arthropod-transmitted infections of man and domesticated animals. Edited by Service, M.W.; Ashford, R.W.; Calidher, C.H.; Eldridge, B.F.; Jones, T.W. and Wyatt, G. . CABI Publishing.

Muskett, J.C., Reed, N.E., Thornton, D.H., 1985. Increased virulence of an infectious bursal disease live virus vaccine after passage in chicks. Vaccine 3, 309-312.

Reed, L.J., Muench, H., 1938. A simple method for estimating fifty percent $(50 \%)$ end points. Amer. J. Hyg. 27, 493-497.
Samuikenko, A.Y.A., Sobolev, V.V., Kanzakov, M.A., Khov, V.V., 1982. Sensitivity of animals (cattle) to FMD virus inoculated at the same time as vaccine. Veterinary Moscow, USSR 1, 24-25.

Theodoridis, A., Boshoff, S.E.T., Botha, M.J., 1973. studies on the development of a vaccine against bovine ephemeral fever. Onderstepoort J. Vet. Res. 40, 77-82.

Traub, E., Manso, I.R., 1944. Uber die herstellung complement bindender merrsch-weinehon sera fur die typendiagnose bie Maul und Klauenseuche. Zbi. Bakt. Lorig. 151, 380381.

Tzipori, S., Spradbrow, P.b., 1973. Studies On Vaccines Against Bovine-Ephemeral Fever. Aust Vet J 49, 183-187.

Uren, M.F., Walker, P.J., Zakrzewski, H.S., George, T.D., Byrne, K.A., 1994. Effective vaccination of cattle using the virion $G$ protein of bovine ephemeral fever virus as an antigen. Vaccine 12, 845-850.

Uren, M.F., Zakrzewski, H., Davis, S.S., 1993. Antibody and cell proliferative responses of cattle vaccinated with bovine ephemeral fever virus proteins. In: St George TD, Uren MF, Young PL, Hoffmann D (eds). roceedings of the 1st International Symposium on Bovine Ephemeral Fever and Related Rhabdoviruses, Beijing, August 1992. Australian Centre for International Agricultural Research Proceedings 44, $122-$ 126.

Wagner, G.G., Card, J.L., Cowan, K.M., 1969. Plum Island Animal Disease Laboratory, Animal Disease and Parasite Research Division Agricultural Research Service. Department of Agricultural, Greanport, New York, USA.

Walker, P.J., Byrne, K.A., Cybinski, D.H., Doolan, D.L., Wang, Y., 1991. Proteins of bovine ephemeral fever virus. J. Gen. Virol. 7267 74.

Walker, P.J., Klement, E., 2015. Epidemiology and control of bovine ephemeral fever. 46:124 DOI10.1186/s13567-015-0262-4.

Zakrzewski, H., Cybinski, D.H., Walker, P.J., 1992. A blocking ELISA for the detection of specific antibodies to bovine ephemeral fever virus. J. Immunol. Methods 151, 289297. 